\title{
Longitudinal analysis of contrast acuity in Friedreich ataxia
}

Ali G. Hamedani, MD, MHS, * Lauren A. Hauser, MS, Susan Perlman, MD, Katherine Mathews, MD, George R. Wilmot, MD, PhD, Theresa Zesiewicz, MD, S.H. Subramony, MD, Tetsuo Ashizawa, MD, Martin B. Delatycki, MD, PhD, Alicia Brocht, MS, and David R. Lynch, MD, PhD

Neurol Genet 2018;4:e250. doi:10.1212/NXG.0000000000000250

\section{Abstract}

\section{Objective}

To determine the natural history of contrast acuity in Friedreich ataxia.

\section{Methods}

In the Friedreich Ataxia-Clinical Outcome Measures Study, participants $(\mathrm{n}=764)$ underwent binocular high- and low-contrast visual acuity testing at annual study visits. Mixed-effects linear regression was used to model visual acuity as a function of time, with random intercepts and slopes to account for intraindividual correlation of repeated measurements. A time-varying covariate was used to adjust for diabetes, and interaction terms were used to assess for effect modification by GAA repeat length, disease duration, and other variables.

\section{Results}

Across a median of 4.4 years of follow-up, visual acuity decreased significantly at $100 \%$ contrast ( -0.37 letters $/ y, 95 \%$ confidence interval $[\mathrm{CI}]:-0.52$ to -0.21$), 2.5 \%$ contrast $(-0.81$ letters/ year, $95 \%$ CI: -0.99 to -0.65$)$, and $1.25 \%$ contrast $(-1.12$ letters/y, $95 \% \mathrm{CI}:-1.29$ to -0.96 letters/year). There was a significant interaction between time and GAA repeat length such that the rate of decrease in visual acuity was greater for patients with higher GAA repeat lengths at $2.5 \%$ contrast $(p=0.018)$ and $1.25 \%$ contrast $(p=0.043)$ but not $100 \%$ contrast. There was no effect modification by age at onset after adjusting for GAA repeat length.

\section{Conclusions}

Low-contrast visual acuity decreases linearly over time in Friedreich ataxia, and the rate of decrease is greater at higher GAA repeat lengths. Contrast sensitivity has the potential to serve as a biomarker and surrogate outcome in future studies of Friedreich ataxia.

\author{
Correspondence \\ Dr. Hamedani \\ Ali.hamedani@uphs.upenn.edu
}




\section{Glossary}

$\mathbf{C I}=$ confidence interval; FA-COMS = Friedreich Ataxia-Clinical Outcome Measures Study; FRDA = Friedreich ataxia; IQR = interquartile range.

Friedreich ataxia (FRDA) is the most common inherited cause of ataxia. ${ }^{1}$ Optic neuropathy is a well-known but underrecognized clinical manifestation of FRDA. ${ }^{2-5}$ Although vision loss is initially mild, ${ }^{6-8}$ it becomes more prominent as the disease progresses, and there are numerous reports of patients who experience dramatic subacute vision loss similar to Leber hereditary optic neuropathy. ${ }^{9-11}$

Low-contrast letter acuity is a well-established clinical correlate of optic nerve disease across multiple neurologic disorders, and in FRDA, it has been found to be associated with predictors of disease severity such as age and GAA repeat length; non-neurologic measures of disease severity such as the presence of diabetes, hearing loss, and cardiomyopathy; and neurologic measures of disease severity such as the Friedreich ataxia rating scale, timed 9-hole peg test (9HPT), and timed 25-foot walk (T25W). ${ }^{12,13}$ Because contrast acuity is easily and reliably measured, there is growing interest in its use as a clinical predictor of disease severity and surrogate outcome in clinical trials for FRDA, particularly among more affected patients.

However, the use of contrast acuity as a biomarker in FRDA is limited by a lack of longitudinal data. To determine the natural history of contrast acuity in these patients, we performed a longitudinal analysis of a large prospective cohort study of patients with FRDA. We hypothesized that contrast acuity would decrease linearly over time and that the rate of decrease would be greater for patients with longer GAA repeat lengths and earlier age at onset.

\section{Methods}

\section{Standard protocol approvals, registration, and patient consents}

Institutional review board approval was obtained at each participating site, and written informed consent was obtained from all patients for participation in the study.

\section{Study design}

The Friedreich Ataxia-Clinical Outcome Measures Study (FA-COMS) is an ongoing prospective cohort study of patients with Friedreich ataxia being followed at one of 12 clinical sites since 2001. ${ }^{14-16}$ Baseline genetic confirmation was obtained via commercial or research testing, and information regarding age at onset and other medical comorbidities was collected. At each annual follow-up visit, participants underwent contrast letter acuity testing using retro-illuminated charts. High-contrast acuity was tested both monocularly and binocularly. Low-contrast acuity was tested binocularly using the $2.5 \%$ and $1.25 \%$ Low-Contrast Sloan Letter Charts at a distance of $2 \mathrm{~m}$ (Precision Vision, LaSalle, IL) using a protocol developed to measure visual dysfunction in MS and Friedreich ataxia, ${ }^{17}$ and the total number of letters correctly identified at each level of contrast was recorded. Visual acuity was measured by trained technicians, and participants wore their standard refractive correction for distance.

\section{Statistical analysis}

Statistical analyses were performed using STATA version 12 (College Station, TX). Multilevel linear regression models were used to model visual acuity at both high and low contrast as a function of time, with a random intercept and slope for each participant to account for intraindividual correlation of repeated measurements. Regression models were adjusted for diabetes using a time-varying covariate to capture both those who had diabetes at baseline and those who were diagnosed with diabetes during the follow-up period. Modification of the effect of time on visual acuity by GAA repeat length and age at onset was assessed using interaction terms. The duration of follow-up was highly variable, with many participants contributing only a single baseline visit and some contributing as many as 12 years of follow-up. To assess for potential information bias due to differential follow-up, linear regression models were constructed for the follow-up duration as a function of baseline demographic characteristics.

\section{Results}

At the time of this analysis, the FA-COMS cohort consisted of 764 patients, of whom $50.4 \%$ were female. The median age at onset was 11 years (interquartile range [IQR]: 7-17), with a median age at the baseline study visit of 23 years (IQR: 15-34). The smaller GAA allele had a median length of 666 repeats (IQR: 466-800), and the baseline prevalence of diabetes was $5 \%$.

Of the 764 patients in the cohort, 332 participated in a single study visit and thus did not contribute data to the longitudinal analysis. The remaining 432 patients were followed up for a median of 5 visits over a median follow-up duration of 4.4 years (IQR: 2.0-6.3). At baseline, mean binocular visual acuity at $100 \%$ contrast was 58.8 letters (IQR: 55-65) of a maximum of 70 , corresponding to a Snellen visual acuity equivalent of $20 / 20$, but $7.6 \%$ of patients had $20 / 40$ acuity or worse. This level of acuity generally qualifies as "visually impaired" and would limit the ability to drive without restrictions in almost all US states. At $2.5 \%$ contrast, the mean number of letters was 31 letters (95\% CI: 25-42), and at $1.25 \%$, it was 25 letters (95\% CI: $14-33$ ). 


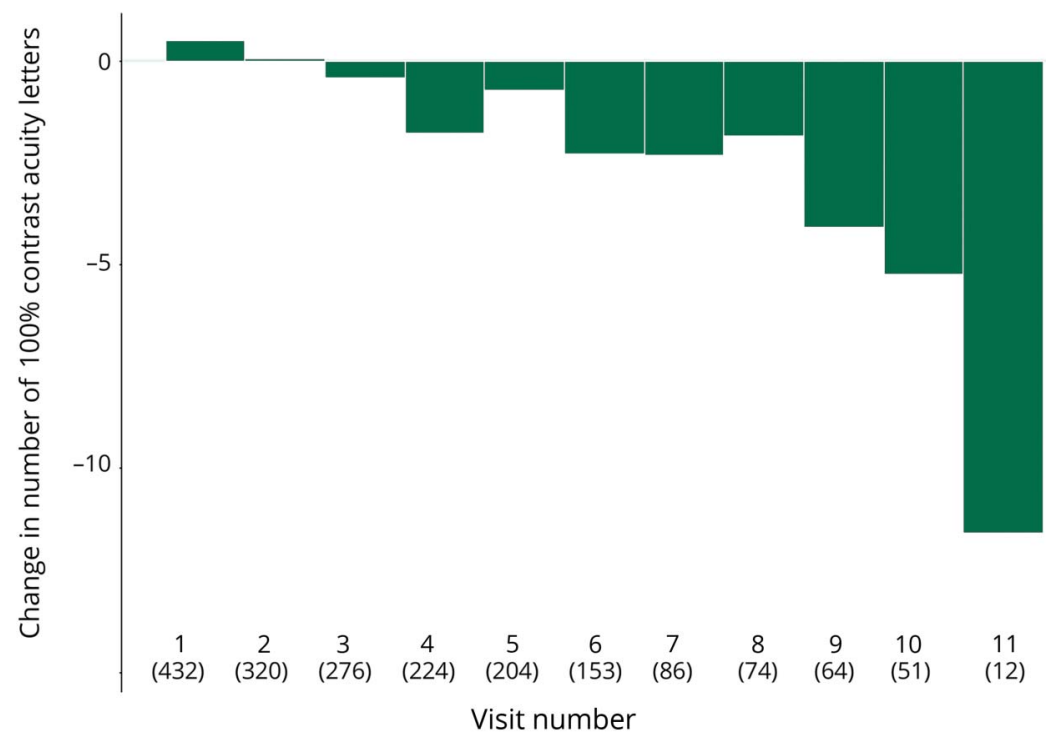

The sample size at each visit is indicated in
parentheses.

The mean difference in visual acuity between each follow-up visit and the baseline study visit at $100 \%, 2.5 \%$, and $1.25 \%$ contrast (figures 1-3), respectively, demonstrated a generally linear pattern of decrease, particularly at low contrast. In diabetes-adjusted multilevel regression models, the average rate of change in vision was -0.37 letters per year at $100 \%$ contrast ( $95 \%$ CI: -0.52 to -0.21 ), -0.81 letters per year at $2.5 \%$ contrast (95\% CI: -0.99 to -0.65$)$, and -1.12 letters per year at $1.25 \%$ contrast $(-1.29$ to -0.96$)$. These estimates did not change after adjusting for sex, age at onset, or GAA repeat length. However, the addition of interaction terms did reveal a significant interaction between the GAA repeat length and time at low contrast but not high contrast. For each additional tertile of GAA triplet repeat, the number of letters lost per year increased by 0.26 letters ( $95 \%$ CI: $0.05-0.47)$ at $2.5 \%$ contrast and 0.21 letters ( $95 \%$ CI: $0.006-0.41$ ) at $1.25 \%$ contrast. There was no significant interaction between the age at onset and time. Using these interaction terms, the predicted time to loss of 7 letters of contrast acuity stratified by tertiles of GAA repeat length and age at onset is shown in tables 1 and 2.

At the final follow-up, mean binocular high-contrast acuity was 57.2 letters, again corresponding to a Snellen equivalent of $20 / 20$. However, the percentage of patients who saw $20 / 40$

Figure 2 Difference in binocular 2.5\% contrast acuity between baseline and follow-up visit

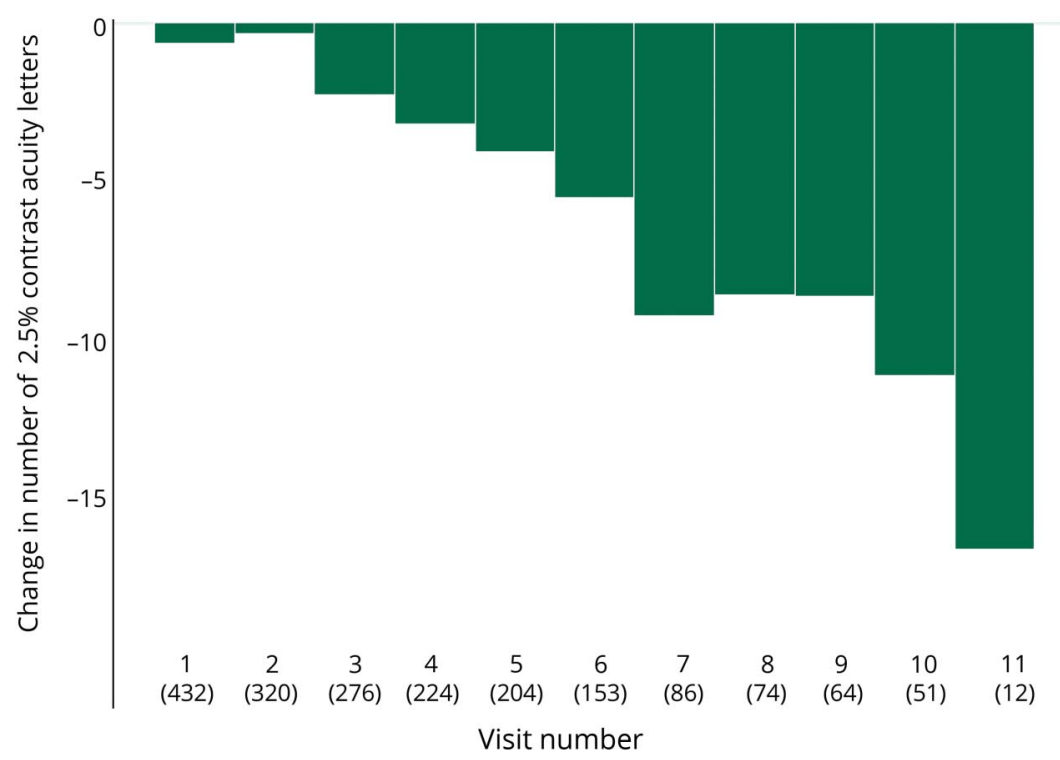

The sample size at each visit is indicated in parentheses. 


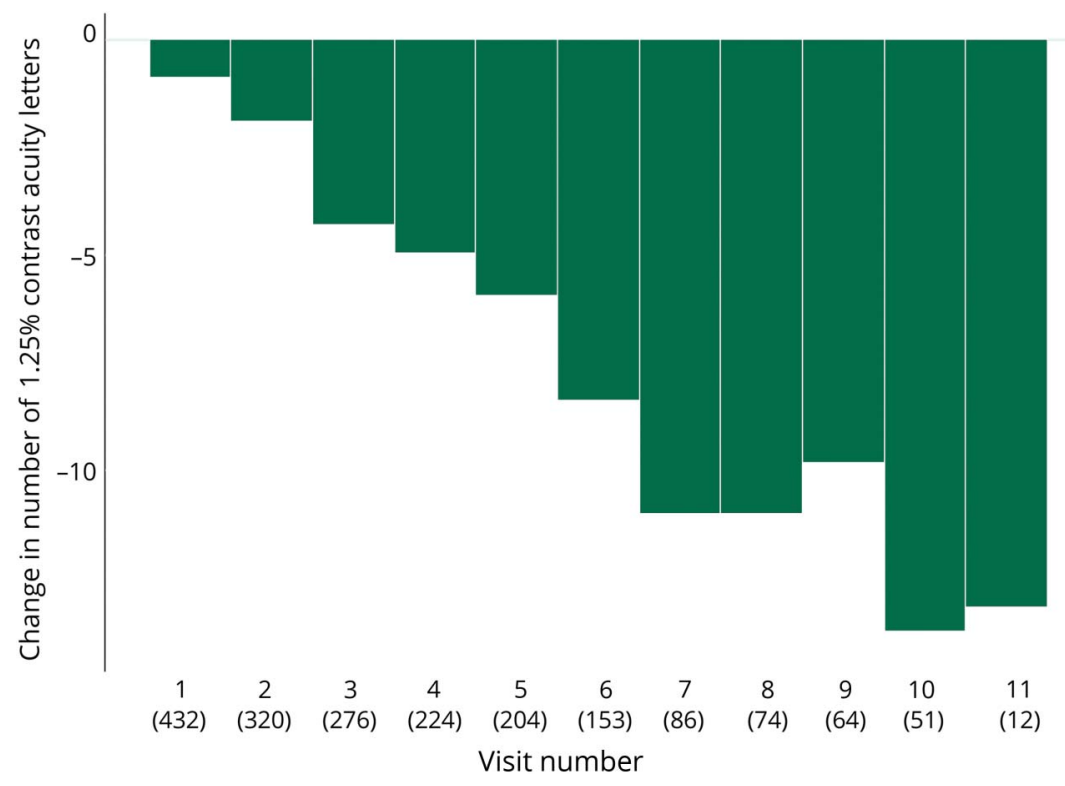

The sample size at each visit is indicated in
parentheses.

or worse increased to $11.9 \%$. Of the 65 patients who were seen at 9 follow-up visits, 11 (16.9\%) saw 20/40 or worse, and of the 12 patients who were seen at all 11 follow-up visits, 4 (33.3\%) saw $20 / 40$ or worse.

Linear regression models were also constructed for the followup duration as a function of baseline demographic variables to assess for information bias due to differential follow-up. In univariate analyses, individuals with a history of hypertrophic cardiomyopathy at baseline had an average of 0.90 less years of follow-up than those without (95\% CI: 0.37-1.42), and the follow-up duration decreased with increasing GAA repeat length ( 0.25 less years per quintile of higher GAA repeat length, 95\% CI: 0.07-0.42). Otherwise, there was no association between age at onset, age at diagnosis, sex, diabetes, or scoliosis and follow-up duration.

\section{Discussion}

In this large prospective cohort study of patients with FRDA, there is a significant essentially linear decrease in low-contrast

Table 1 Estimated number of years to loss of 7 letters of binocular $2.5 \%$ contrast acuity stratified by minimum GAA repeat length and age at onset

\begin{tabular}{llll}
\hline $\begin{array}{l}\text { Age at } \\
\text { onset, } y\end{array}$ & $\begin{array}{l}\text { Minimum } \\
\text { GAA }<\mathbf{5 1 0}\end{array}$ & $\begin{array}{l}\text { Minimum } \\
\text { GAA 512-733 }\end{array}$ & $\begin{array}{l}\text { Minimum } \\
\text { GAA 738-1320 }\end{array}$ \\
\hline$<\mathbf{8}$ & 22 & 8.6 & 5.3 \\
\hline $\mathbf{9 - 1 5}$ & 20 & 8.2 & 5.2 \\
\hline$>\mathbf{1 6}$ & 18 & 7.9 & 5.1 \\
\hline
\end{tabular}

acuity over time that is greater in subjects with higher GAA repeat lengths. High-contrast acuity is also affected, but this becomes apparent only at longer follow-up intervals. This reduction in low-contrast acuity but sparing high-contrast acuity likely reflects subtle optic nerve dysfunction. Contrast sensitivity also relies on higher-order cortical visual integration, and recent studies have found evidence of cognitive impairment in FRDA including with visuospatial reasoning, so it is possible that this reduction in low-contrast acuity is multifactorial in etiology. ${ }^{18}$ However, cognitive impairment in FRDA is extremely mild and detectable only by detailed neuropsychological testing and thus is unlikely to affect contrast sensitivity. The fact that low-contrast acuity demonstrates a predictable decrease over time that depends on an internal predictor of disease severity (namely, GAA repeat length) supports its use as a potential biomarker in future studies. As a biomarker, low-contrast acuity has the advantage of being easily and reliably measured. This may be particularly relevant for gene therapy, in which treatment delivery remains a challenge, particularly for inherited CNS diseases. Development and validation of vision-based outcomes open the

Table 2 Estimated number of years to loss of 7 letters of binocular $1.25 \%$ contrast acuity stratified by minimum GAA repeat length and age at onset

\begin{tabular}{llll}
\hline $\begin{array}{l}\text { Age at } \\
\text { onset, } \mathbf{y}\end{array}$ & $\begin{array}{l}\text { Minimum } \\
\text { GAA }<\mathbf{5 1 0}\end{array}$ & $\begin{array}{l}\text { Minimum } \\
\text { GAA 512-733 }\end{array}$ & $\begin{array}{l}\text { Minimum } \\
\text { GAA 738- } \\
\mathbf{1 3 2 0}\end{array}$ \\
\hline $\mathbf{8}$ & 8.9 & 6.6 & 5.3 \\
\hline $\mathbf{9 - 1 5}$ & 7.7 & 6.0 & 4.9 \\
\hline $\mathbf{1 6}$ & 7.0 & 5.4 & 4.9 \\
\hline
\end{tabular}


door to retinal gene therapy as a potential proof of concept in Friedreich ataxia and as a clinically relevant therapeutic intervention.

Despite being one of the largest cohorts of its kind, our study experienced sample size limitations, particularly at longer follow-up intervals. Although this was primarily due to censoring (and possibly mortality, given the association between hypertrophic cardiomyopathy and shorter follow-up duration) rather than loss to follow-up, this nevertheless introduces the potential for information bias. This becomes particularly relevant when calculating the time to loss of 7 letters, as our estimates of low-contrast acuity at 5-10 years are extrapolated from data collected primarily at $0-5$ years. Furthermore, although 7 letters of low contrast represent 1 line of Snellen acuity equivalent and has been validated as a clinically meaningful outcome in MS and other patient populations because it is associated with detectable reductions in vision-related quality of life, it has not been specifically validated in Friedreich ataxia. The degree of low-contrast acuity loss is similar in Friedreich ataxia compared with $\mathrm{MS}^{14}$ but this does not guarantee a similar reduction in visionrelated quality of life because long-standing impairment may go unnoticed or be well compensated by early adaptive mechanisms. A recent survey of patients with FRDA and their families as part of a patient-focused drug development meeting identified vision loss as a concern, particularly when compounded on other sources of disability, ${ }^{19}$ and in this cohort, a notable proportion of the population had symptomatic vision loss defined as $20 / 40$ or worse, especially later in the disease course. However, future studies of low-contrast acuity and vision-related quality of life are needed in Friedreich ataxia if it is to be used as a biomarker or surrogate outcome.

\section{Author contributions}

A.G. Hamedani: conceived the study, performed primary statistical analysis, and drafted the manuscript. L. Hauser: critically reviewed the manuscript. S. Perelman, K. Mathews, G.R. Wilmot, T. Zesiewicz, S.H. Subramony, T. Ashizawa, M.B. Delatycki, and A. Brocht: participated in initial data collection and critically reviewed the manuscript. D.R. Lynch: conceived the study and critically reviewed the manuscript.

\section{Study funding}

T. Zesiewicz holds intellectual property for the use of nicotinic agonists in cerebellar ataxias and nonataxic imbalance. $T$. Ashizawa's spouse has equity in Bio-Path Holdings.

\section{Disclosure}

A.G. Hamedani and L. Hauser report no disclosures. S. Perelman receives research support from the Friedreich's Ataxia Research Alliance and the National Ataxia Foundation; receives support for clinical trials from Biohaven Pharmaceuticals, Horizon Pharma, Reata Pharmaceuticals, Retrotope, Takeda Pharmaceuticals, and Teva; and has received funding from EryDel, ViroPharma/Shire, Edison, and Pfizer for past clinical trial studies. K. Mathews receives support for clinical trials from Horizon Pharma; has served on the scientific advisory boards of DSMB, Santhera, Sarepta, BMS, and MSA; has received research funding from the NIH, the $\mathrm{CDC}$, and the Friedreich's Ataxia Research Alliance; and has received research support from PTC Therapeutics, Sarepta Therapeutics, Eli Lilly, aTyr, Pfizer, FibroGen, Roche, and Italfarmaco for clinical trials. G.R. Wilmot receives research support from the National Ataxia Foundation and Friedreich's Ataxia Research Alliance and support for clinical trials from Reata Pharmaceuticals and Biohaven Pharmaceuticals; has served on the Santhera Pharmaceuticals Scientific Advisory Board for Biohaven Pharmaceuticals; and has received research support from Reata Pharmaceuticals and Biohaven Pharmaceuticals. T. Zesiewicz receives research support from the Friedreich's Ataxia Research Alliance and support for clinical trials from Retrotope, Biohaven Pharmaceuticals, Reata Pharmaceuticals, Takeda Pharmaceuticals, Pfizer, Sagene Pharmaceuticals, AbbVie, Cavion, Bristol-Myers Squibb, and Sage Therapeutics. She has received consulting fees from Steminent Inc; has served on the editorial board of Neurodegenerative Disease Management; holds a patent for varenicline in the treatment of ataxia; and served as a consultant for Steminent Inc. S.H. Subramony receives research support from the NIH, Friedreich's Ataxia Research Alliance, National Ataxia Foundation, Muscular Dystrophy Association, and Myotonic Dystrophy Association and support for clinical trials from Horizon Pharma, Reata Pharmaceuticals, Ionis Pharmaceuticals, and Acceleron Pharma; has served on the editorial board of the Handbook of Clinical Neurology, 2011 edition; and has received research support from the NIH and STTR. T. Ashizawa receives research support and serves on the scientific advisory boards of the NIH, National Ataxia Foundation, and Myotonic Dystrophy Association; holds a patent for the DNA test for SCA10, PVA or PEG conjugates of peptides for epitope specific immunosuppression and for the methods and compositions involving nucleotide repeat disorders; and has received research support from Ionis Pharmaceuticals, Biohaven Pharmaceuticals, Biogen, NINDS, the Weill Cornell Medical Colleges, and the Marigold Foundation. M.B. Delatycki receives research support from the National Health and Medical Research Council, Friedreich's Ataxia Research Alliance, and Friedreich Ataxia Research Association; has served on the editorial board of BMC Pediatric Genetics; and has received research funding from FARA USA and Australia. A. Brocht reports no financial disclosures. D.R. Lynch receives research support from the NIH, Friedreich's Ataxia Research Alliance, and U.S. Food and Drug Administration; receives support for clinical trials from Reata Pharmaceuticals and Horizon Pharma; has received funding for travel from Franklin and Marshall College; serves on the editorial board of the Journal of Neurogenetics; holds a patent for the test for anti-NDMA receptor encephalitis; and has received research funding from Takeda Pharmaceuticals and ENTRADA Therapeutics. Full disclosure form information provided by 
the authors is available with the full text of this article at Neurology.org/NG.

Received December 23, 2017. Accepted in final form May 22, 2018.

\section{References}

1. Campuzano V, Montermini L, Molto MD, et al. Friedreich's ataxia: autosomal recessive disease caused by an intronic GAA triplet repeat expansion. Science 1996;271: 1423-1427.

2. Harding AE. Clinical features and classification of inherited ataxias. Adv Neurol 1993; 61:1-14.

3. Epstein E, Farmer JM, Tsou A, et al. Health related quality of life measures in Friedreich ataxia. J Neurol Sci 2008;272:123-128.

4. Tsou AY, Paulsen EK, Lagedrost SJ, et al. Mortality in Friedreich ataxia. J Neurol Sci 2011;307:46-49.

5. Newman N. Hereditary optic neuropathies. In: Miller N, Newman N, editors. Walsh \& Hoyt: Clinical Neuro-Ophthalmology, Vol. 1, 5th ed. Baltimore: Williams \& Wilkins; 1999:741-773.

6. Carroll WM, Kriss A, Baraitser M, Barrett G, Halliday AM. The incidence and nature of visual pathway involvement in Friedreich's ataxia: A clinical and visual evoked potential study of 22 patients. Brain 1980;103:413-434.

7. Fortuna F, Barboni P, Liguori R, et al. Visual system involvement in patients with Friedreich's ataxia. Brain 2009;132:116-123.

8. Pinto F, Amantini A, de Scisciolo G, Scaioli V, Guidi L, Frosini R. Visual involvement in Friedreich's ataxia: PERG and VEP study. Eur Neurol 1988;28:246-251.
9. Givre SJ, Wall M, Kardon RH. Visual loss and recovery in a patient with Friedreich ataxia. J Neuroophthalmol 2000;20:229-233.

10. Diehl B, Lee MS, Reid JR, Nielsen CD, Natowicz MR. Atypical, perhaps underrecognized? An unusual phenotype of Friedreich ataxia. Neurogenetics 2010;11 261-265.

11. Porter N, Downes SM, Fratter C, Anslow P, Nemeth AH. Catastrophic visual loss in a patient with Friedreich ataxia. Arch Ophthalmol 2007;125:273-274.

12. Seyer LA, Galetta K, Wilson J, et al. Analysis of the visual system in Friedreich ataxia. J Neurol 2013;260:2362-2369.

13. Lynch DR, Farmer JM, Tsou AY, et al. Measuring Friedreich ataxia: complementary features of examination and performance measures. Neurology 2006;66: $1711-1766$

14. Friedman LS, Farmer JM, Perlam S, et al. Measuring the rate of progression in Friedreich ataxia: implications for clinical trial design. Mov Disord 2010;25:426-432.

15. Patel M, Isaacs CJ, Seyer L, et al. Progression of Friedreich ataxia: quantitative characterization over 5 years. Ann Clin Transl Neurol 2016;3:684-694.

16. Baier ML, Cutter GR, Rudick RA, et al. Low-contrast letter acuity testing captures visual dysfunction in patients with multiple sclerosis. Neurology 2005;64:992-995.

17. Lynch DR, Farmer JM, Rochestie D, Balcer LJ. Contrast letter acuity as a measure of visual dysfunction in patients with Friedreich ataxia. J Neuroophthalmol 2002;22: 270-274.

18. Nieto A, Correia R, de Nobrega E, Monton F, Barroso J. Cognition in late-onset Friedreich ataxia. Cerebellum 2013;12:504-512.

19. Friedreich's Ataxia Research Alliance et al. The Voice of the Patient: Summary report resulting from an externally led Patient-Focused Drug Development Meeting, a parallel effort to the US Food and Drug Administration's (FD's) Patient-Focused Drug Development Initiative. 2017. 


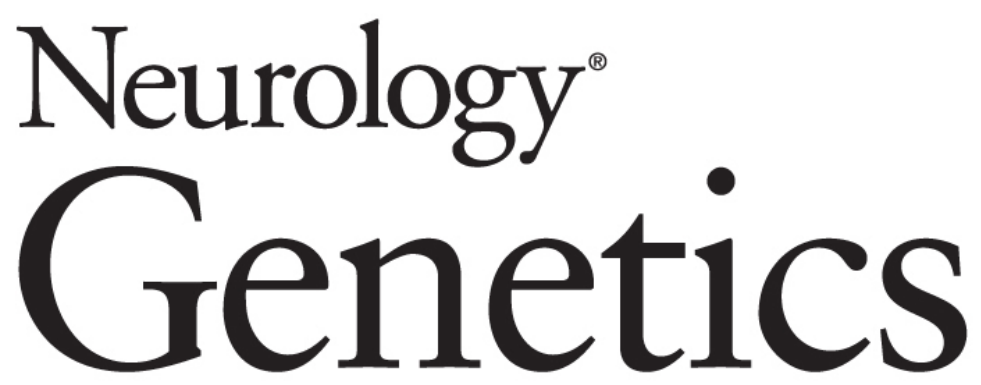

Longitudinal analysis of contrast acuity in Friedreich ataxia Ali G. Hamedani, Lauren A. Hauser, Susan Perlman, et al. Neurol Genet 2018;4;

DOI 10.1212/NXG.0000000000000250

This information is current as of July 23, 2018

Neurol Genet is an official journal of the American Academy of Neurology. Published since April 2015, it is an open-access, online-only, continuous publication journal. Copyright Copyright (C) 2018 The Author(s). Published by Wolters Kluwer Health, Inc. on behalf of the American Academy of Neurology.. All rights reserved. Online ISSN: 2376-7839.

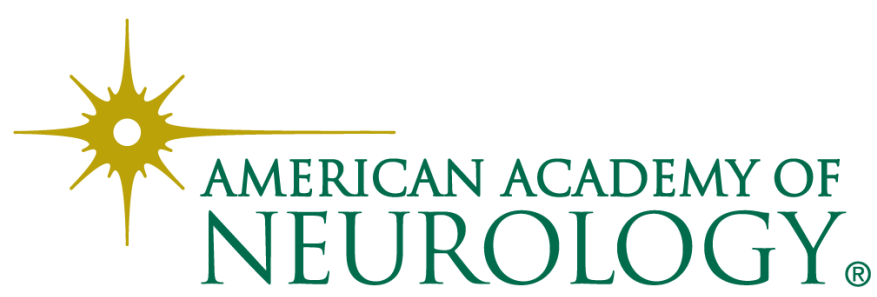




\section{Updated Information \& Services}

References

Citations

Subspecialty Collections

Permissions \& Licensing

Reprints including high resolution figures, can be found at: http://ng.neurology.org/content/4/4/e250.full.html

This article cites 18 articles, 1 of which you can access for free at: http://ng.neurology.org/content/4/4/e250.full.html\#\#ref-list-1

This article has been cited by 1 HighWire-hosted articles: http://ng.neurology.org/content/4/4/e250.full.html\#\#otherarticles

This article, along with others on similar topics, appears in the following collection(s):

\section{Cohort studies}

http://ng.neurology.org//cgi/collection/cohort_studies

Natural history studies (prognosis)

http://ng.neurology.org//cgi/collection/natural_history_studies_prognos is

Optic nerve

http://ng.neurology.org//cgi/collection/optic_nerve

Spinocerebellar ataxia

http://ng.neurology.org//cgi/collection/spinocerebellar_ataxia

Trinucleotide repeat diseases

http://ng.neurology.org//cgi/collection/trinucleotide_repeat_diseases

Information about reproducing this article in parts (figures,tables) or in its entirety can be found online at:

http://ng.neurology.org/misc/about.xhtml\#permissions

Information about ordering reprints can be found online:

http://ng.neurology.org/misc/addir.xhtml\#reprintsus

Neurol Genet is an official journal of the American Academy of Neurology. Published since April 2015, it is an open-access, online-only, continuous publication journal. Copyright Copyright $\odot 2018$ The Author(s). Published by Wolters Kluwer Health, Inc. on behalf of the American Academy of Neurology.. All rights reserved. Online ISSN: 2376-7839.

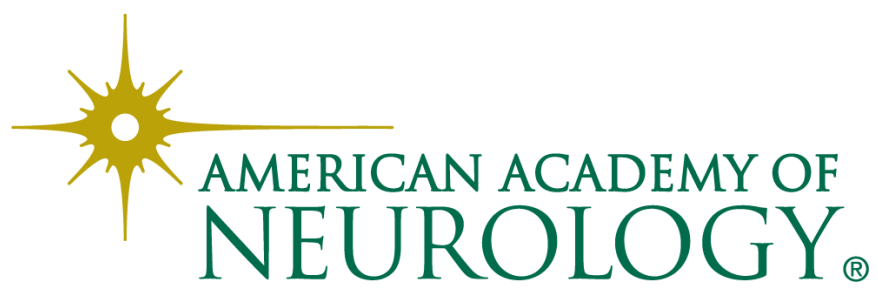

